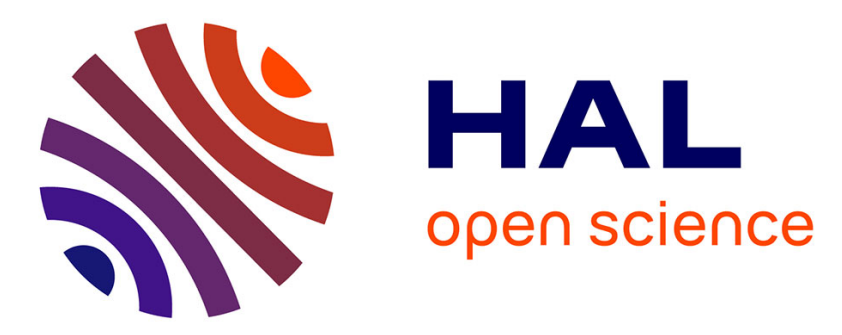

\title{
Study by X-Ray microtomography of the horizontal vibration effects on sand densification
}

L. Olmos, Jean-Marc Chaix, Sébastien Nadler, Olivier Bonnefoy, Jean-Louis Gelet, Gérard Thomas

\section{- To cite this version:}

L. Olmos, Jean-Marc Chaix, Sébastien Nadler, Olivier Bonnefoy, Jean-Louis Gelet, et al.. Study by X-Ray microtomography of the horizontal vibration effects on sand densification. Granular Matter, 2016, 18 (3), pp.61. 10.1007/s10035-016-0661-x . hal-01346078

\section{HAL Id: hal-01346078 \\ https://hal.science/hal-01346078}

Submitted on 21 Jul 2016

HAL is a multi-disciplinary open access archive for the deposit and dissemination of scientific research documents, whether they are published or not. The documents may come from teaching and research institutions in France or abroad, or from public or private research centers.
L'archive ouverte pluridisciplinaire HAL, est destinée au dépôt et à la diffusion de documents scientifiques de niveau recherche, publiés ou non, émanant des établissements d'enseignement et de recherche français ou étrangers, des laboratoires publics ou privés. 


\title{
Study by X-Ray microtomography of the horizontal vibration effects on sand densification
}

\author{
L. Olmos ${ }^{\mathrm{a} 1^{*}}$, J.-M. Chaix ${ }^{\mathrm{a}}$, S. Nadler ${ }^{\mathrm{b}}$, O. Bonnefoy ${ }^{\mathrm{b}}$, J.-L. Gelet ${ }^{\mathrm{c}}$, G. Thomas ${ }^{\mathrm{b}}$
}

${ }^{a}$ SIMAP, Grenoble INP-CNRS-UJF, BP 75, F-38402 Saint-Martin d'Hères, France

${ }^{\mathrm{b}}$ Centre SPIN, LPMG UMR CNRS 5148, Ecole Nationale Supérieure des Mines de Saint-Etienne, 158 Cours Fauriel, F-42023 Saint-Etienne Cedex 2, France

${ }^{c}$ MERSEN, 6 rue de Vaucanson, F-69720 Saint-Bonnet de Mure, France

${ }^{1}$ Coordinación de la Investigación Científica, Universidad Michoacana de San Nicolás de Hidalgo, Ed. C-2 en C.U., Fco. J. Mujica S/N, Col. Centro, C.P. 58060, Morelia, México.

*corresponding author email: luisra24@ gmail.com Tel: (+52) 44336979 40. Fax: (+52) 44331674 36.

\begin{abstract}
$\mathrm{X}$ ray microtomography experiments were performed in order to evaluate the densification of silica sand submitted to horizontal sinusoidal vibrations carried out at constant frequency $(50 \mathrm{~Hz})$ with controlled acceleration and deceleration $\Gamma$. Packing homogeneity was characterized using relative density distribution through 3D images of the relaxed samples. Information obtained from the images allowed us to evaluate data at grain scale: porosity and pore size distribution, number of contacts per particle, particle shape and size distribution were evaluated and linked to the densification process. Based on the internal analysis of samples, the results confirm and extend the conclusions of previous works regarding the 3-layer densification under vibration and the proposed optimized vibration cycle to get dense and homogeneous samples. They extend them to different initial packings. Additionally, significant correlations are found between density and local particle packing characteristics such as pores size distribution, or the number of contacts per particle.
\end{abstract}

Keywords: X ray microtomography; horizontal vibration; densification; porosity, sand packing. 


\section{Introduction}

Granular media are extensively used in many industries such as, e.g., mines, agriculture, pharmaceutical, powder metallurgy and electrical fuses. High density and good homogeneity are key points to ensure the targeted properties. Nevertheless, obtaining a dense packing from a random or heterogeneous initial configuration is a hard task. One of the most classical methods consists in vibrating the packing. Many experimental and analytical works have been dedicated to understand the behavior of grains during a short period of shaking, using vertical vibration [1-12] or horizontal vibration [13-24]. In this work, we are interested in the behavior of grains under horizontal vibration. Some works focused on the investigation of two main phenomena: the transition from solid to liquid behavior of the granular medium $[15,19]$, and the convective cellular flow during vibration [16-18, 20-22]. The characteristics of the grains and of the container walls play an important role on the behavior of the vibrated packing [16]. However these works paid less attention to the microstructure reached after vibration. Raihane et al. [23] have calculated the dynamic and relaxed compactness of a vibrated sand packing. They identified three zones referred to as fluidized, glassy and jammed regions, characterized by different values of the density. This information was however deduced from outside analysis of particle motion through the transparent container wall, and has to be confirmed by an analysis inside the packing. In most industrial processes, homogeneous and compacted packing is required to ensure the performance and reliability of the device or post-processing. X-ray microtomography is a relatively new technique well suited for the analysis of porous and granular materials and structures. It has been used for studying cohesive behavior of pharmaceutical powders during vibration [25], the microstructure of rocks in soil mechanics [26,27], bulk grains of wheat and pea grains for storage strategies [28], polymer, metallic and ceramic foams [29-32], compaction [3336], sintering [37-40]. The aim of this work is to study the microstructure of vibrated sand packings used in high intensity electrical fuses by the Mersen Company. During their manufacture horizontal vibration is applied in order to compact the sand in a ceramic box which contains the silver fuse. The behavior of those devices is strongly dependent on the sand microstructure which needs to be both 
homogeneous and well compacted. In this work, the relaxed microstructure of a vibrated packing is analyzed by X-ray microtomography after horizontal vibration with a special attention paid to the effect of the relative acceleration $\Gamma$ (with respect to gravity acceleration $g$ ). Additional features of individual (shape, size of particles) or collective (coordination, porosity) grains are investigated and are linked to the final microstructure.

\section{Experimental}

The experimental device has been described in previous works [22-23]. It consists in a mobile horizontal table, on which a fixed container is partially or fully filled with the granular material. The electromagnetic shaker (Tira TV51110) delivers a sinusoidal vibration with controlled frequency (f); in our experiments, it was kept constant at $50 \mathrm{~Hz}$. The effect of the frequency was studied by Mendez et al. [25] in pharmaceutical powders and they found that density increased as the frequency did too in the range of 2 to $8 \mathrm{~Hz}$. The amplitude A was monitored by a power amplifier (Tira BAA 120) associated with a sinusoidal vibration control system (Ling Dynamic Systems DSC4). Coupled with a piezoelectric accelerometer (Bruel \& Kjaer $4371 \mathrm{~V}$ ) attached to the vibrating table, the control system adapts the amplitude A to the chosen acceleration $\Gamma$ which was varied from 0 to 9 . In this study, the feed-back loop was deactivated, so that the target acceleration was reached within approximately $1 \mathrm{~s}$. The sand container is a transparent Plexiglas box with a base of $15 \times 15 \mathrm{~mm}^{2}$ and $80 \mathrm{~mm}$ height, which has a very low absorption coefficient of the $\mathrm{X}$ rays. It was filled with silica sand for two different heights of 40 and $80 \mathrm{~mm}$. Dimensions of the box were chosen with the compromise between the capability of the tomography equipment (Nanotom) and the resolution of the images. The behavior of grains observed from the outside of the box during the shaking was similar to that observed for larger boxes. 
The powders used are composed of silica sand with more than $99 \%$ of alpha-quartz and a density of $2660 \mathrm{~kg} / \mathrm{m}^{3}$. No internal close porosity has been detected: the pycnometer density determination shows that the grain density corresponds to the crystal one. The particle size distribution was established by 3D image analysis. For that purpose it was performed a particle segmentation by a watershed procedure applied on binary images (for more details refer to Vagnon et al. [38]). The volume and the centre of gravity of each particle were then calculated from the segmented images.

Then the diameter $d$ is computed from the volume $V$ of each particle (equivalent sphere diameter $=$ $(6 \mathrm{~V} / \pi)^{1 / 3}$. Particle diameters range from 200 to $750 \mu \mathrm{m}$ (Figure 1). The volume weighed average diameter $(564 \mu \mathrm{m})$ was $10 \%$ higher than the number weighed $(506 \mu \mathrm{m})$.

Powders were poured into the container using three different protocols in order to create initial packings with different degrees of heterogeneity. In the first case, sand powders were simply poured through a $15 \mathrm{~mm}$ diameter funnel until the box was filled. The second one consisted in pouring sand powders into the container through a narrow $5 \mathrm{~mm}$ funnel situated approximately $50 \mathrm{~mm}$ above the free surface. During the filling, the funnel was moved here and there to form an almost regular and flat sand bed. The final small excess of sand grains was then carefully removed using vacuum cleaner. The final granular packing height is $40 \mathrm{~mm}$. When carefully applied, this protocol ensures a reproducible and relatively low density with a rather good homogeneity of the packing. The third one is the pluviation (sand raining) technique: in this classic technique $[41,42]$ the box is filled by dropping the sand grains slowly from a distance of $100 \mathrm{~mm}$ using a $15 \mathrm{~mm}$ diameter funnel, and passing throughout of a mesh with a mean diameter of $1 \mathrm{~mm}$. This technique leads to relative densities higher than $65 \%$. So the initial average relative densities of the samples studied here ranged from 0.55 to 0.66 . Then the box was placed on the vibrating table, and vibrated at constant $\Gamma$ during 30 seconds. After vibration, the sample was carefully transferred to the tomography device. We used a different sample for each condition, but each sample was observed by microtomography before and after vibration.

\section{Tomography analysis}


The microtomography experiments were performed in a Phoenix Nanotom providing an X-ray beam with high energy voltage on the range between 0 and $180 \mathrm{kV}$. In the present experiments, $90 \mathrm{kV}$ were used, enabling X-ray to pass through the sample with a good contrast and resolution for the final images. A thin layer of copper was used as a filter of the $\mathrm{X}$ ray beam to reduce the beam hardening effects and neither streaking, shading and ring artifacts were observed in the reconstructed 3D images. Because the samples (with an $80 \mathrm{~mm}$ height) are too high, it was necessary to take two tomographic series by moving up smoothly the sample with respect to the axis of the X-ray beam which stays at the same position after the first tomography was done. In order to obtain the whole sample on a reconstructed single 3D image, a common volume (overlap) is taken in both tomographies. This volume can be easily detected and ensures the continuity of the information in the whole sample. For each one, 2300 radiographies were taken at different angles all around the $360^{\circ}$ and the distance between the sample and the detector or X-ray source was adjusted to get a voxel size of $19 \mu \mathrm{m}$. The resolution in the images was chosen regarding the size of the sample and the size of grains; and it was enough to get quantitatively information about the grains and porosity from a macroscopically point of view.

3D images were reconstructed (absorption coefficient) using the algorithm included in the Phoenix Nanotom software package. Then the whole 3D image volumes (800x800x2300 pixels) were filtered with the plug-ins included in the Image J program, both unsharp mask and median filters were used to enhance the contrast between grains and pores. A thresholding procedure was then applied to separate the solid phase from the porous one. We use a manual thresholding constrained with the global relative density that was previously measured on the whole sample from mass and volume. In the obtained binary images, the solid phase was represented by a voxel intensity of 255 and the pore phase by a voxel intensity of 0 . The relative density was calculated dividing the number of voxels contained in the solid phase by the total number of voxels evaluated in each of the images.

These images were used to get the distribution of the relative density in the whole sample. To calculate the 3D density map, the sample was divided into sub-volumes (300x300x300 voxels, i.e. $5.7 \times 5.7 \times 5.7$ $\mathrm{mm}^{3}$ ). These sub-volumes are considered representative as each of them contains about 800 particles. 
The relative density is measured as the number fraction of sand voxels. This leads to mean values of density on a 3D grid of 5X5X $\mathrm{H}$ points ( $\mathrm{H}$ depends on the height of the sand packing). Interpolation was performed using the Matlab software to obtain pseudo-continuous representations such as Figure 2.

The pore size distribution was evaluated using the 3D openings technique $[43,44]$, which characterizes the porous volume accessible to a structural element with increasing size, previously used by other authors [39-40,45-46] for interconnected porosity. This procedure consists on sequential 3D morphological openings (erosion then dilation) with increasing sizes of the structural element; octahedra were used in the present work. After each opening, the remaining volume fraction (number of voxels) is measured, so that a frequency histogram of "accessible volume" vs. size can be plotted.

To obtain information of the particles at the micro-scale, a segmentation of particles as individual objects is needed. This was achieved using the watershed (ultimate erosions) algorithm [44] ("split convex" function in the Aphelion software). As the particle segmentation could not be achieved on the whole image because of its large size, the image was divided in sub-volumes (300x300x300 pixels). An overlap between adjacent volumes was used to prevent artifacts due to particles crossed by the volume edges. Each particle is defined by the spatial coordinates of its center of mass (x, y, and z) and its volume, so that the duplicates could be easily removed. The particle sphericity $S p$, defined as the surface area of a sphere enclosing the same volume $\mathrm{V}$ as the 3D object was estimated from:

$$
S p=6 V \sqrt{\frac{\pi}{S^{3}}}
$$

where $V$ and $S$ are the particle volume and surface respectively.

This classic parameter, derived from the Saltykov 3D shape index [47] was used to describe the shape of rocks [48], is an indicator of the irregularity of particles. As $S p$ gets closer to 1 the particle is closer to a spherical shape. 
The particle coordination number $(Z)$ was also used: contact areas were obtained from intermediate images of the particle separation process. In those images, each object (particle or contact area) was tagged and labeled, so that the contacts associated to each particle (distance $<1$ voxel) were identified as well as list of particles touching it. The mean coordination number was calculated for each subvolume. This method induces a slight overestimation of the coordination number due to the nonzero image resolution [34] which can be corrected as a function of the resolution and the mean particle size as proposed by Vagnon et al. [38]. This correction was applied to the results presented in this paper, the value estimated is 0.62 .

\section{Results}

The first series of measurements were carried out using $80 \mathrm{~mm}$ as maximal altitude and pouring the grains quickly into the container by the first method described above. The average initial relative density was around $0.55 \pm 0.004$ for the whole sample. The density map (Figure 2 ) shows that density is not homogeneous along the vertical axis ( $\mathrm{z}=$ distance to the bottom): an intermediate layer $(\mathrm{z}=10$ to $40 \mathrm{~mm}$ ) of lower density $51-54 \%$ ), while it is around 0.56 in the upper part and can reach values up to $60 \%$ close to the bottom. This effect is due to the highly uncontrolled filling method, which also leads to poor reproducibility in the density profiles, but the initial structure will rapidly be changed by vibrations.

After vibration, the average density continuously increases as far as higher accelerations $\Gamma$ are applied. Densification occurs at all points of the volume, but in a non-homogeneous way (Figure2). After vibration at high acceleration $(\Gamma=5)$ the container is divided into two almost homogeneous areas: the upper part shows a high density (0.64-0.66, red on Figure 2) while the bottom one shows a lower one (0.59-0.61) but significantly higher than the initial density. That behavior was observed by Mendez et al. [25] when they increased the number of taps on the different cohesive powders. The high density area clearly appears as after vibration at $\Gamma=1$, then expands towards the bottom after higher acceleration vibrations: the typical thickness increases from 10 to $40 \mathrm{~mm}$, i.e. half of the sample. At 
intermediate accelerations, the lower part of the sample shows a higher density than in the initial state, but the initial structure is clearly seen at $\Gamma=1$.

After vibration, the surface has a mountain-like profile (Figure 3), more pronounced as $\Gamma$ increases, so that the mean density measurements using the sub-volumes method could not be performed.

In order to analyze the effects of the starting state (density and homogeneity), we performed experiments by slowly filling the container till an altitude around $40 \mathrm{~mm}$, using a funnel of $5 \mathrm{~mm}$ as described in the experimental section. The initial average relative density obtained was $0.58 \pm 0.002$, this value was about $6 \%$ higher than the one obtained with the rapid filling method. Figure 4 shows the density distribution inside the samples. For the not vibrated sample, the initial density distribution was almost homogeneous $(0.58 \pm 0.01)$. The vibrated samples leaded to similar observations as in the case of rapid filling, i.e., the development of a high density layer (read area on Figure 4), which grows towards the bottom as the acceleration of vibrations is increased. In the bottom of the samples, the density is slightly increased to reach values around 0.6, i.e. almost the same density as in previous experiments, although the starting density was different. Above the high density layer, a lower density layer can be observed (truncated on Figures 2 and 4).

These results suggest that vibrations with high accelerations tend to densify through the development of the high density zone. Previous works [23] had shown on samples with an initial density around 0.61 that, in practice, the density first increases with acceleration but decreases for high accelerations. They also showed that, if acceleration is progressively reduced after having reached such high values, an increased final density can be obtained. These experiments was reproduced here with different initial packings obtained with the 3 above mentioned packing methods (rapid, slow, pluviation) using initial packing heights of 40 and $80 \mathrm{~mm}$. The samples were vibrated at a maximal acceleration $\Gamma_{m}$ of 9 and 11 for 40 and $80 \mathrm{~mm}$ high samples, respectively for 30 seconds, and then the acceleration was slowly decreased to zero in about 1 minute. Figure 5 shows the density distribution inside the vibrated samples. The initial samples rapidly filled show lower densities, and samples with height of $80 \mathrm{~mm}$ 
exhibit higher heterogeneity. The rapidly filled sample presented a lower density with more heterogeneous distribution. The sample filled by raining (pluviation) was highly densified $(C=0.66)$, and very homogeneous, except for the part close to the surface where the relative density was slightly lower. After observing the vibration cycle all samples were well and homogeneously densified whatever was the altitude or the filling method used to prepare the samples. A small $4 \mathrm{~mm}$ thick zone close to the surface of the sample appears to have a lower density although the mountain like profile is no longer observed after the vibration cycle used here.

As indicated above, the porosity of the samples was characterized by the pore size distribution by the openings method with an octahedral as structuring elements. Figure 6a shows the cumulative volume fraction for the samples filled with a funnel and vibrated at different $\Gamma$. The size of pores is reduced as $\Gamma$ increases, which was expected since relative density increases too. The median size of pores $d_{50 \text { pore }}$ was reduced by about $30 \%$ for the denser sample as well as the difference between the size of pores $d_{10 \text { pore }}$ and $d_{90 \text { pore }}(\operatorname{span})$. In Figure $6 \mathrm{~b}$ are plotted the pore size distribution of the samples vibrated at $\Gamma$ $=9$ then $\Gamma$ reduced to 0 for the three different kinds of filling. The pore size distribution is similar for all samples wherever the kind of filling used, which confirms that the difference between samples, if any, is very small.

The median pore size was normalized by the median grain size $\left(\mathrm{d}_{50 \text { part }}\right.$ volume size distribution) and plotted versus the relative density (Figure 7). This ratio $d_{50 \text { pore }} / d_{50 \text { part }}$ was calculated on the $5 X 5 X 5 \mathrm{~mm}^{3}$ subvolumes of all samples and the whole volume of each sample. The pore size clearly decreases with increasing density. The obtained correlation provides an empirical correlation law which confirms the intuitive expectation. It is important to notice that the mean pore size is reduced by a factor of about two when density is changed from 0.53 to 0.68 , which is the highest value that could be achieved with this silica sand.

Two additional parameters of the sand packing were measured and related to density, through the mean values computed on the whole samples and on the subvolumes, in order to get complementary 
information: sphericity $S_{\mathrm{p}}$, which characterizes the shape of grains and the coordination number $\mathrm{Z}$, which characterizes the environment of grains inside the packing.

The coordination number measured on subvolumes from the samples without vibration, and vibrated at $\Gamma 1$ and 5 are reported on Figure 8 . The tendency of the coordination number to increase with packing density is usual, in crystallographic ordered packings as well as in random particle packings [33, 40, and 43]. It is interesting to notice that densification not only leads to a shift of the subvolume points towards higher density and coordination numbers on the same curves, but also tends to reduce the dispersion of the corresponding clusters of points, which is an indicator of increasing homogeneity. That behavior was observed for spherical non cohesive particles in dynamic simulations by using the discrete element method $[49,50]$. They also pointed out that the particle shape has an influence on the relative density and coordination number. In their works both relative density and coordination number were increased as the aspect ratio (L/D) was increased too which means that sphericity is reduced.

The average sphericity for the sand is 0,814 , and individual sphericity values range between 0.6 and 1 , with $90 \%$ between 0.7 and 0.9 (Figure 9). Some grains of different sphericity are shown in Figure 9b to illustrate the shapes associated to the Sp values. The mean sphericity of grains measured for each subvolume decreases as the relative density increases [Figure10]. This is any unexpected result as the particle shape is an intrinsic characteristic of particles, which should not "depend" on density. Moreover, the average sphericity, if we consider the mean value on all subvolumes decreases from 0.814 to 0.803 when vibration increases. One must therefore imagine that particles themselves are modified by the vibration process. Indeed, the shift of the shape factor values is small. This could indicate that particle surfaces are slightly smoothed by the shocks and friction during vibrations, but no sign of fine dust resulting from such phenomena has been observed on the samples. Another alternative is that this observation is related to the increase of coordination and to image resolution: the contacts between particles result in small flat areas, which can produce the observed small shift of 
apparent shape factor. This could be also affected by method of watershed used to separate the particles in the 3D images. Anyway, this illustrates that such results must be handled very carefully.

\section{Discussion}

From external observations from outside the sample, Raihane et al. [22, 23] proposed an interpretation of densification phenomena leading to the structuration of packing in 3 main layers from observation during vibration (“dynamic") and after vibration ("relaxed"). Their work was mainly based on external observations of the samples. At the top of the sand packing, the upper layer is fluidized (and expanded) during the vibration process, then leads after relaxation to an intermediate range of densities (typically around 0.62 ) when vibration is stopped. This region extends when acceleration is increased. The second layer, just below, grows towards the bottom when acceleration is increased: it is the place of local rearrangement which leads to high densification and to final density between 0.64 and 0.67. The last layer is a jammed one at the bottom of the packing, where the effect of the horizontal vibration is practically unnoticeable, and limited to a small density increase is observed (estimated to less than 0.02) when the first vibrations are applied, whatever the densification is. This zone is located below the denser zone and the densification is lower than $2 \%$. Their experiments were obtained from rather homogeneous initial samples with an initial density around 0.61 , in rather large containers $\left(40 \mathrm{X} 80 \mathrm{~mm}^{2}\right)$. The present experiments confirm these observations through the density maps inside the samples after the vibrations. Quantitative values, in particular the layers thicknesses, cannot be compared because of two main differences: the box size and the initial packings. The box size was in the present case driven by the need to have a high enough resolution to analyze particles and density maps in the same image. The 3 particle packings ( 3 initial states) studied in single acceleration experiments (Figures 2 and 4 ) show that, whatever the initial homogeneity and density, the process evolves in the same manner: small densification of the bottom and formation of a dense intermediate layer which develops from top towards the bottom.

Beyond these single acceleration experiments, the technique proposed by Raihane et al. [23] to get high density homogeneous samples using high acceleration $\Gamma_{\mathrm{m}}$ followed by a slow decrease of 
acceleration. Here again, the predictions of these authors, deduced from experiments with a different container and initial density, are confirmed. Whatever the initial density, whatever the maximum acceleration $\Gamma$ used, provided it is high enough to ensure the full fluidization of the sand bed, and for two different heights of the initial sand packings, the samples final relative density distribution of the relaxed microstructures is the same homogeneous one inside the container and reach the value of 0.68 already obtained by Raihane et al. in their experiments. This homogeneity is confirmed by the pore size distributions showed in Figure $6 \mathrm{~b}$ where it is observed that all curves are similar for the three 40 mm high samples.

Pore size distributions (Figure 6) are also markers of densification: densification tends to a limit density distribution with minimal mean value and narrow size distribution, the distribution width (span d90-d50) being also related to inhomogeneity. The correlation of the pore size " $\mathrm{d}_{50 \text { pore }}$ " with relative density, studied on subvolumes over wide range of densities ( 0.53 to 0.68 , Figure 7$)$ shows that the pore size normalized by the particle average size decreases from more than 0.5 to 0.26 in that density range.

The number of contacts per particle also shows a strong correlation with density, which is also what is observed in other situations such as pressure induced compaction and sintering [40], but with different values.

The apparent correlation with of density and the shape of grains, which is probably an artifact due to the grain segmentation and a consequence of the increase of contact numbers when density is increased illustrate that this kind of correlation must be analyzed very carefully.

\section{Conclusion}

This work based on X-Ray microtomography to perform an internal analysis of sand packed by vibrations has led to two kinds of results:

1. The confirmation and extension of results which, in previous papers, were only based on measurements made from external observation at macroscopic scale: overall density, particle 
motion observed through the transparent wall of the vibrated recipients. They appear as complementary which were needed to fully validate the results.

2. The measurement of internal local characteristics and packing parameters using sub-volumes. Useful correlations have been found: homogeneity/density and pore size distribution, number of contacts per particle and density, etc. with practical quantitative values for the studied sand. The need for a very careful and critical minded analysis of data was also illustrated with the observed correlation between measured shape factor and density has also been pointed out.

X-Ray microtomography therefore appears as a useful tool to get data in such systems and opens new possibilities. The next step will be to search for relationships between the local organization obtained by vibrations in these sand packings, such as thermal conductivity or permeability through the porous network between particles.

\section{References}

[1] Fauve, S., Douady, S., Laroche, C.: Collective behaviours of granular masses under vertical vibrations, J. Phys. 50, 187-191(1989).

[2] Douady, S., Fauve, S., Laroche, C.: Subharmonic Instabilities and Defects in a Granular Layer under Vertical Vibrations, Europhys. Lett. 8, 621-627 (1989).

[3] Melo, F., Umbanhowar, P., Swinney, H.: Transition to parametric wave patterns in a vertically oscillated granular layer, Phys. Rev. Lett. 72, 172-175 (1994).

[4] Aoki, K.M., Akiyama, T., Maki, Y.J., Watanabe, T.: Convective roll patterns in vertically vibrated beds of granules, Phys. Rev. E 54, 874-883 (1996).

[5] Knight, J.B., Ehrichs, E.E., Kuperman, V.Yu., Flint, J.K., Jaeger, H.M., Nagel, S.R.: Experimental study of granular convection, Phys. Rev. E 54, 5726-5738 (1996).

[6] McNamara, S., Luding, S.: Energy flows in vibrated granular media, Phys. Rev. E 58, 813-822 (1998). 
[7] Bizon, C., Shattuck, M.D., Swift, J.B., McCormick, W.D., Swineey, H.L.: Patterns in 3D

Vertically Oscillated Granular Layers: Simulation and Experiment, Phys. Rev. Lett. 80, 57-60 (1998).

[8] Tennakoon, S.G.K., Behringer, R.P.: Vertical and Horizontal Vibration of Granular Materials:

Coulomb Friction and a Novel Switching State, Phys. Rev. Lett. 81, $794-797$ (1998).

[9] Hsiau, S.S., Chen, C.H.: Granular convection cells in a vertical shaker, Powder Technol. 111, 210217 (2000).

[10] Rouèche, E., Thomas, G., Gelet, J.L., Missiaen, J.M.: Dependence of granular arrangements under vibrations on the dimensions of cylindrical containers, in: R. Gardia-Rojo, H.J. Herrmann, S. Mc Namara (Eds.), Powder \& Grains, vol. 2, Balkema, 1177-1180 (2005).

[11] Huang, K., Zhang, P., Miao, G., Wei, R.: Dynamic behaviors of supersonic granular media under vertical vibration, Ultrasonics 44, e1487-e1489 (2006).

[12] Eshuis, P., van der Weele, K., van der Meer, D., Bos, R., Lohse, D.: Phase diagram of vertically shaken granular matter, Phys. Fluids 19, 123301-1-11 (2007).

[13] Lee, J.: Scaling behavior of granular particles in a vibrating box, Physica A 219, 305-326 (1995).

[14] Liffman, K., Metcalfe, G., Cleary, P.: Granular Convection and Transport due to Horizontal Shaking, Phys. Rev. Lett. 79, 4574-4576 (1997).

[15] Ristow, G.H.: Phase Diagram and Scaling of Granular Materials under Horizontal Vibrations, Phys. Rev. Lett. 79, 833-836 (1997).

[16] Grossman, E.L.: Effects of container geometry on granular convection, Phys. Rev. E 56, 32903300 (1997).

[17] Medved, M., Dawson, D., Jaeger, H.M., Nagel, S.R.: Convection in horizontally vibrated granular material, Chaos 9, 691- 696 (1999).

[18] Hsiau, S.S., Ou, M.Y., Tai, Chi-H.: The flow behavior of granular material due to horizontal shaking, Adv. Powder Technol. 13, 167-180 (2002).

[19] Mayor, P., D’Anna, G., Gremaud, G., Barrat, A., Loreto, V.: Mechanical spectroscopy of vibrated granular matter, Mat. Sci. Eng. A-Struct. 442, 256-262 (2006).

[20] Zeilstra, C., Collignon, J.G., van der Hoef, M.A., Deen, N.G., Kuipers, J.A.M.: Experimental and numerical study of wall-induced granular convection, Powder Technol. 184, 166-176 (2008). 
[21] Lu, Li-Shin, Hsiau, Shu-San: Mixing in a vibrated granular bed: Diffusive and convective effects, Powder Technol. 184, 31-43 (2008).

[22] Raihane, A., Bonnefoy, O., Gelet, J.-L., Chaix, J.-M., Thomas, G.: Experimental study of a 3D dry granular medium submitted to horizontal shaking, Powder Technol. 190, 252-257 (2009). [23] Raihane, A., Bonnefoy, O., Chaix, J.-M. , Gelet, J.-L., Thomas, G.: Analysis of the densification of a vibrated sand packing, Powder Technol. 208, 289-295 (2011).

[24] Metzger, M.J., Remy, B., Glasse, B.J.: All the Brazil nuts are not on top: Vibration induced granular size segregation of binary, ternary and multi-sized mixtures, Powder Technol. 205, 42-51 (2011).

[25] Mendez, R., Romansky, F.S., Tomassone, M.S.: Density behavior of cohesive granular materials, Powder Technol. 211, 189-198 (2011).

[26] Biswal, B., Manwart, C., Hilfer, R., Bakke, S., Øren, P.E.: Quantitative analysis of experimental and synthetic microstructures for sedimentary rock, Physica A: Statistical Mechanics and its Applications 273, 452-475 (1999).

[27] Peth, S.: Chapter 3 - Applications of Microtomography in Soils and Sediments, Developments in Soil Science 34, 73-101 (2010).

[28] Neethirajan, S., Jayas, D.S., White, N.D.G., Zhang, H.: Investigation of 3D geometry of bulk wheat and pea pores using X-ray computed tomography images, Comput. Electron. Agric. 63, 104-111 (2008).

[29] Trater, A.M. , Alavi, S., Rizvi, S.S.H.: Use of non-invasive X-ray microtomography for characterizing microstructure of extruded biopolymer foams, Food Res. Int. 38, 709-719 (2005). [30] Petrasch, J., Wyss, P., Steinfeld, A.: Tomography-based Monte Carlo determination of radiative properties of reticulate porous ceramics, J. Quant. Spectrosc. Ra. 105, 180-197 (2007).

[31] Goodall, R., Marmottant, A., Salvo, L., Mortensen, A.: Spherical pore replicated microcellular aluminium: Processing and influence on properties, Mat. Sci. Eng. A-Struct. 465, 124-135 (2007). [32] Saadatfar, M., Garcia-Moreno, F., Hutzler, S., Sheppard, A.P., Knackstedt, M.A., Banhart, J., Weaire, D.: Imaging of metallic foams using X-ray micro-CT, Colloid. Surface A 344, 107-112 (2009). 
[33] Richard, P., Philippe, P., Barbe, F., Bourles, S., Thibault, X., Bideau, D.: Analysis by x-ray microtomography of a granular packing undergoing compaction, Phys. Rev. E, Statistical, nonlinear, and soft matter physics 68, 020301.1-020301.4 (2003).

[34] Marmottant, A., Salvo, L., Martin, C.L., Mortensen, A.: Coordination measurements in compacted $\mathrm{NaCl}$ irregular powders using X-ray microtomography, J. Eur. Ceram. Soc. 28, 2441-2449 (2008).

[35] Lhuissier, P., Fallet, A., Salvo, L., Brechet, Y.: Quasistatic mechanical behaviour of stainless steel hollow sphere foam: Macroscopic properties and damage mechanisms followed by X-ray tomography, Mater. Lett. 63, 1113-1116 (2009).

[36] Fu, X., Elliot, J.A., Bentham, A.C., Hancock, B.C., Cameron, R.E.: Application of X-ray Microtomography and Image Processing to the Investigation of a Compacted Granular System, Part. Part. Syst. Charact. 23, 229-236 (2006).

[37] Lame, O., Bellet, D., Di Michiel, M., Bouvard, D.: Bulk observation of metal powder sintering by X-ray synchrotron microtomography, Acta Mater. 52, 977-984 (2004).

[38] Vagnon, A., Rivière, J.P., Missiaen, J.M., Bellet, D., Di Michiel, M., Josserond, C., Bouvard, D.: 3D statistical analysis of a copper powder sintering observed in situ by synchrotron microtomography, Acta Mater. 56, 1084-1093 (2008).

[39] Olmos, L., Takahashi, T., Bouvard, D., Martin, C.L., Salvo, L, Bellet, D., Di Michiel, M.: Analysing the sintering of heterogeneous powder structures by in situ microtomography, Philos. Mag. A 89, 2949-2965 (2009).

[40] Olmos, L., Martin, C.L., Bouvard, L, Bellet, D., Di Michiel, M.: Investigation of the Sintering of Heterogeneous Powder Systems by Synchrotron Microtomography and Discrete Element Simulation, J. Am. Ceram. Soc. 92, 1492-1499 (2009).

[41] Vaid, Y.P., Negussey, D.: Preparation of reconstituted sand specimens, in Advanced Triaxial Testing of Doil and Rock, ASTM STP 977, R.T. Donaghe, R. C. Cnaney, Eds., ASTM, 405-417 (1988).

[42] Wood, F.M., Yamamuro, J.A., Lade, P.V.: Effect of depositional method on the undrained response of silty sand, Can. Geotech. 45, 1525-1537 (2008). 
[43] Matheron, G.: Eléments Pour une Théorie des Milieux Poreux, Masson, Paris, (1967).

[44] Serra, J.: Image analysis and mathematical morphology Academic Press, London (1982).

[45] Babin, P., Della Valle, G., Chiron, H., Cloetens, P., Hoszowska, J., Pernot, P., Réguerre, A.L.,

Salvo, L., Dendievel, R.: Fast X-ray tomography analysis of bubble growth and foam setting during breadmaking, J. Cereal Sci. 43, 393-397 (2006).

[46] Maire, E., Colombo, P., Adrien, J., Babout, L., Biasetto, L.: Characterization of the morphology of cellular ceramics by 3D image processing of X-ray tomography, J. Eur. Ceram. Soc. 27, 1973-1981 (2007).

[47] Saltykov, S.A.: Stereometrische Metallographie Metallurgizdat, VEB, Leipzig, (1974).

[48] Lin, C.L., Miller, J.D.: 3D characterization and analysis of particle shape using X-ray microtomography (XMT), Powder Technol. 154, 61-69 (2005).

[49] Deng, X.L., Davé, R.N.: Dynamic simulation of particle packing influenced by size, aspect ratio and surface energy, Granul. Matter 15, 401-415 (2013).

[50] Wouterse, A., Luding, S., Philipse, A.P.: On contact numbers in random rod packings, Granul. Matter 11, 169-177 (2009). 
Figure captions

Fig. 1 Particle size distribution of the sand grains: cumulative plots of volume and number fractions.

Fig. 2 Density distribution (projection along the vibration axis) for $80 \mathrm{~mm}$ height samples vibrated with different accelerations $\Gamma$ in the case of the rapid filling method. The sand volume is truncated a few mm below the top of the sand packing, to prevent biasing due to the non-planar shape (Figure3)

Fig. 3 Vertical cross section and 3D external view of packing near the upper surface of the horizontal vibrated sand after vibration at $\Gamma=3$.

Fig. 4 Density distribution inside the sample (initial packing height: $40 \mathrm{~mm}$ ) vibrated at different accelerations $\Gamma$ in the case of the slowly filling method.

Fig. 5 Density distributions inside the samples vibrated at high $\Gamma$ then $\Gamma$ reduced to 0 for different filling methods and heights.

Fig. 6 Pore size distribution of the whole samples; a) of the sample with $40 \mathrm{~mm}$ height vibrated at different accelerations and $b)$ three different filling methods and vibrated with the densifying cycle $(\Gamma$ $=9$ then progressive $\Gamma$ decrease down to 0 ).

Fig. 7 Dependence of the median pore size (normalized by the median grain diameter) on the relative density for the $5 \times 5 \times 5 \mathrm{~mm}^{3}$ sub-volumes of samples before and after vibrated or not with accelerations $\Gamma$ between 1 and 9 the red triangles mark the average values for the whole $15 \times 15 \times 40 \mathrm{~mm}^{3}$ samples Fig. 8 Correlation between relative density and coordination number, for sub volumes of 3 rapidly filled samples without vibration and after vibration at $\Gamma=1$ and 5 .

Fig. 9 Particle sphericity distribution for the studied sample (a) and examples of particles with different shapes (b)

Fig. 10 Correlation between relative density and the average particle sphericity for sub volumes of 3 rapidly filled samples without vibration and after vibration at two different $\Gamma 1$ and 5 (a). Illustration of small shape (and sphericity) modifications due to contacts (b): due to nonzero pixel size, contacts appear as almost flat areas and not as "points". 
Figure 1

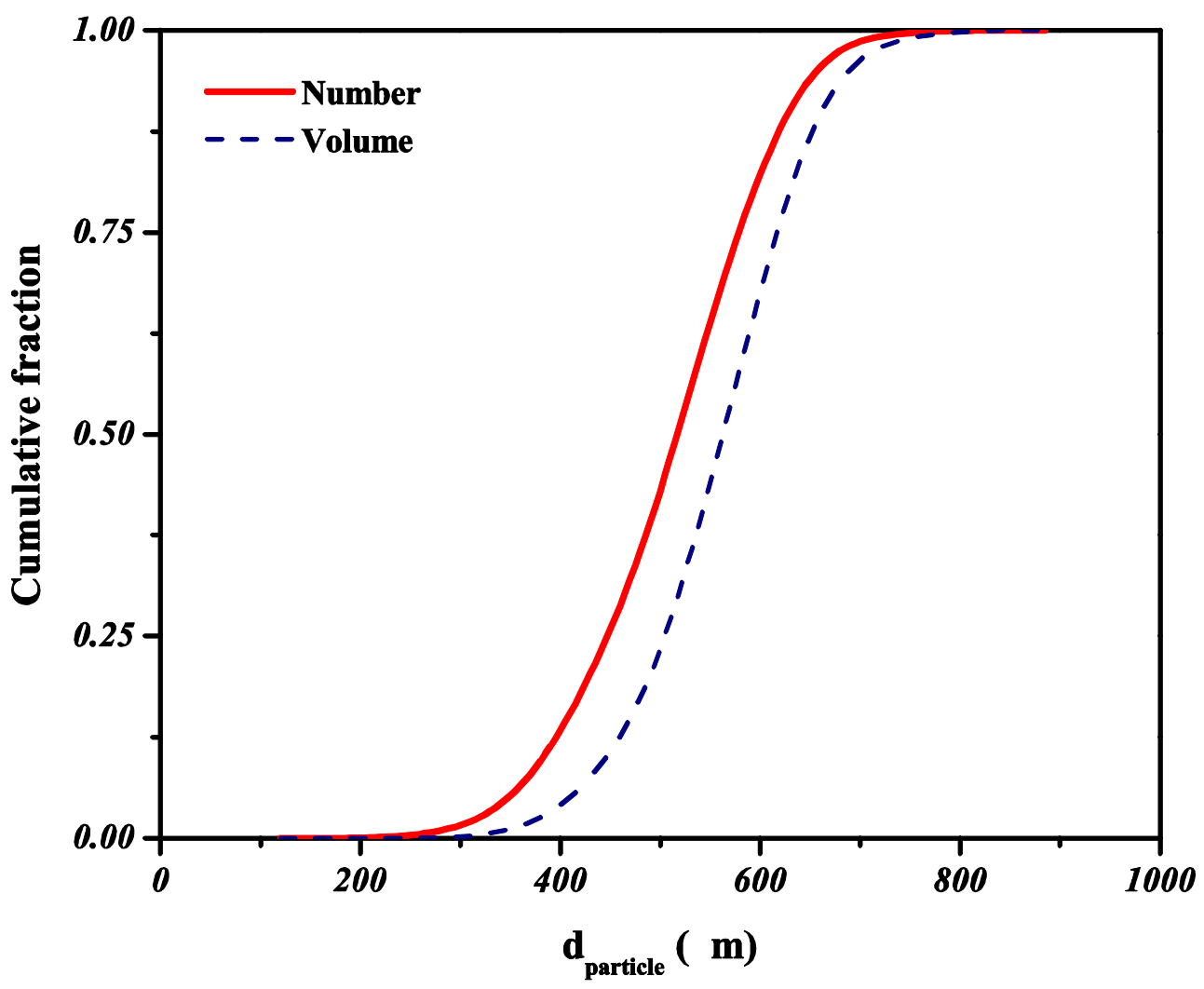


Figure 2

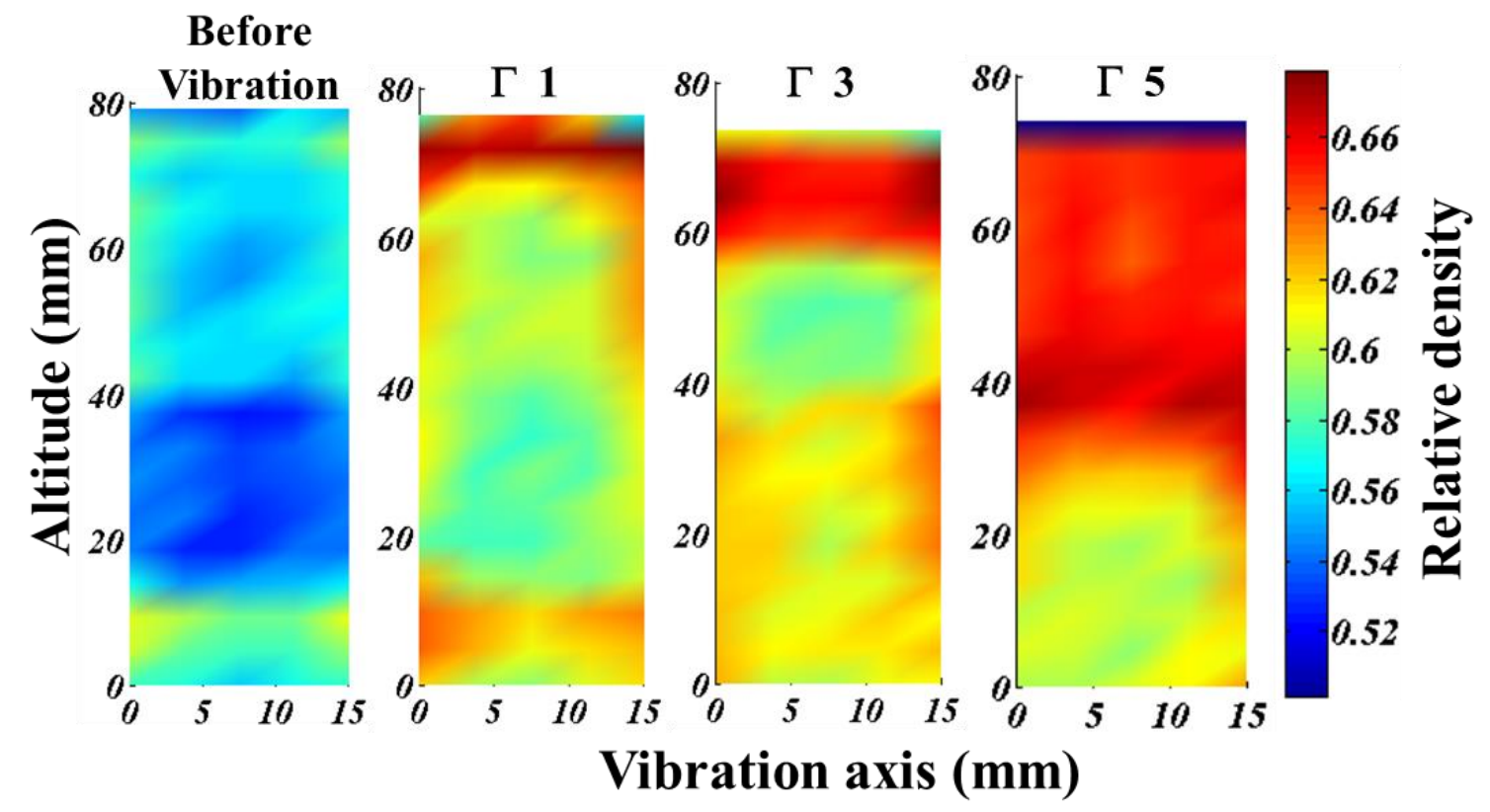


Figure 3

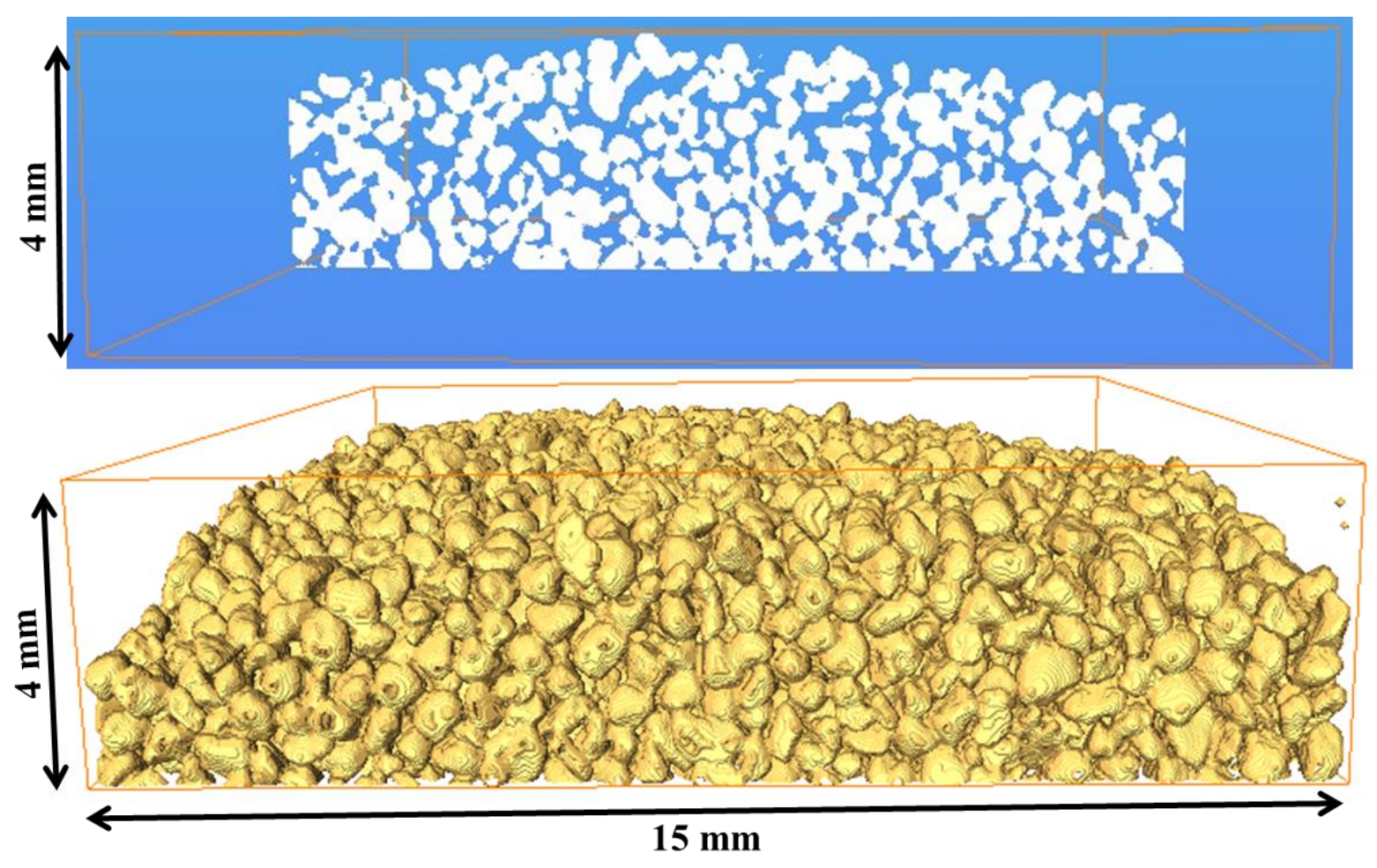


Figure 4

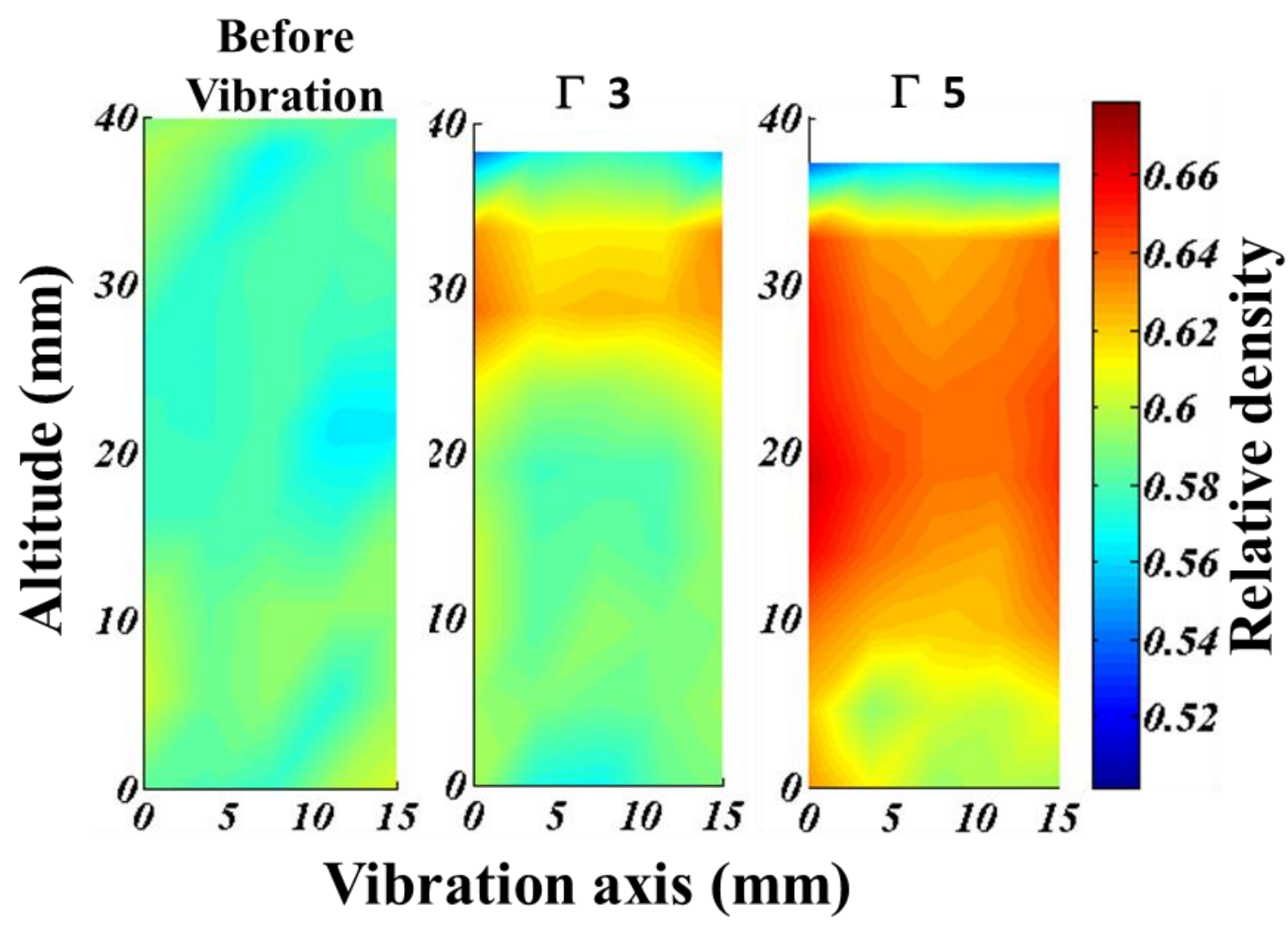


Figure 5

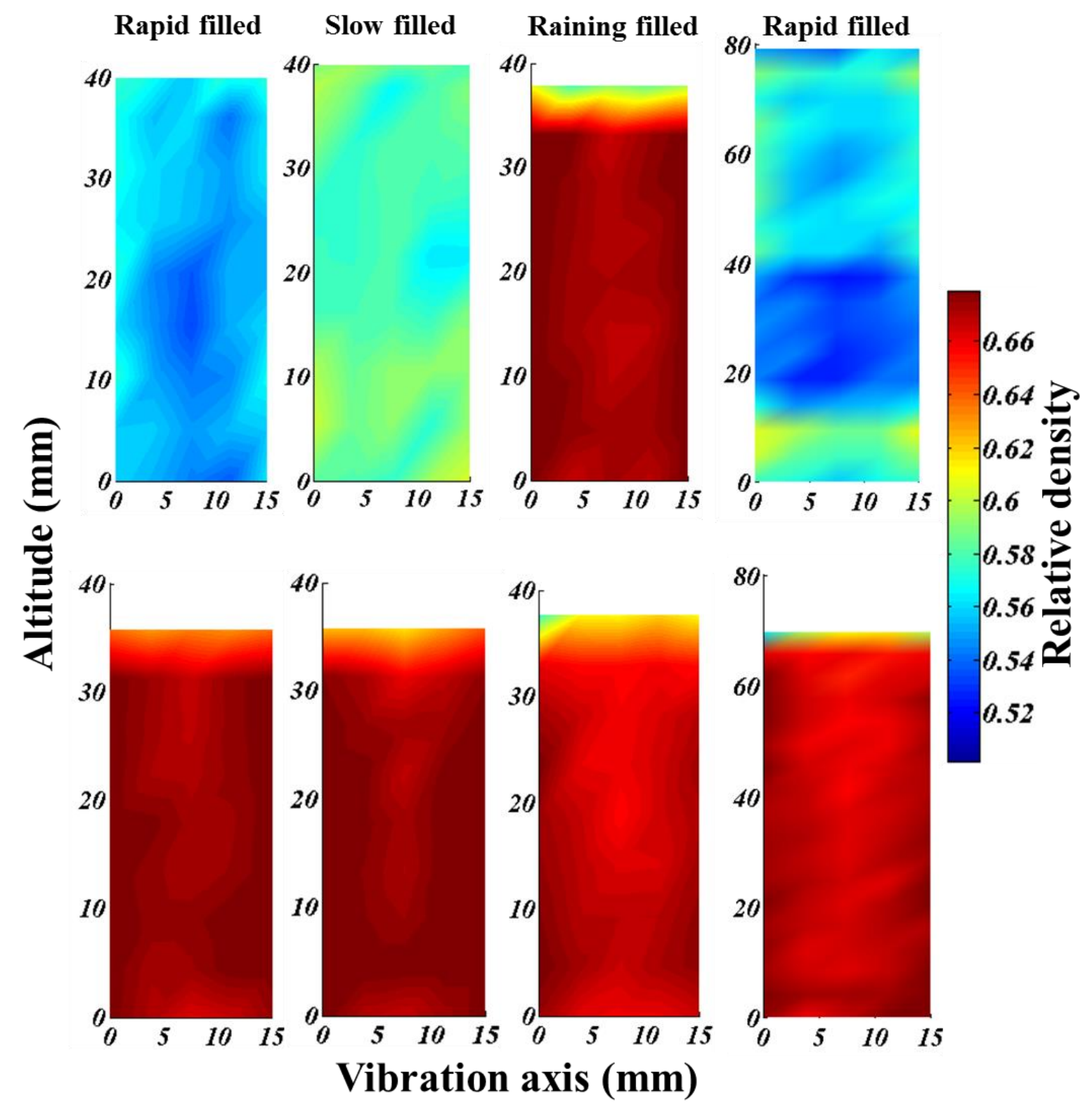


Figure 6a

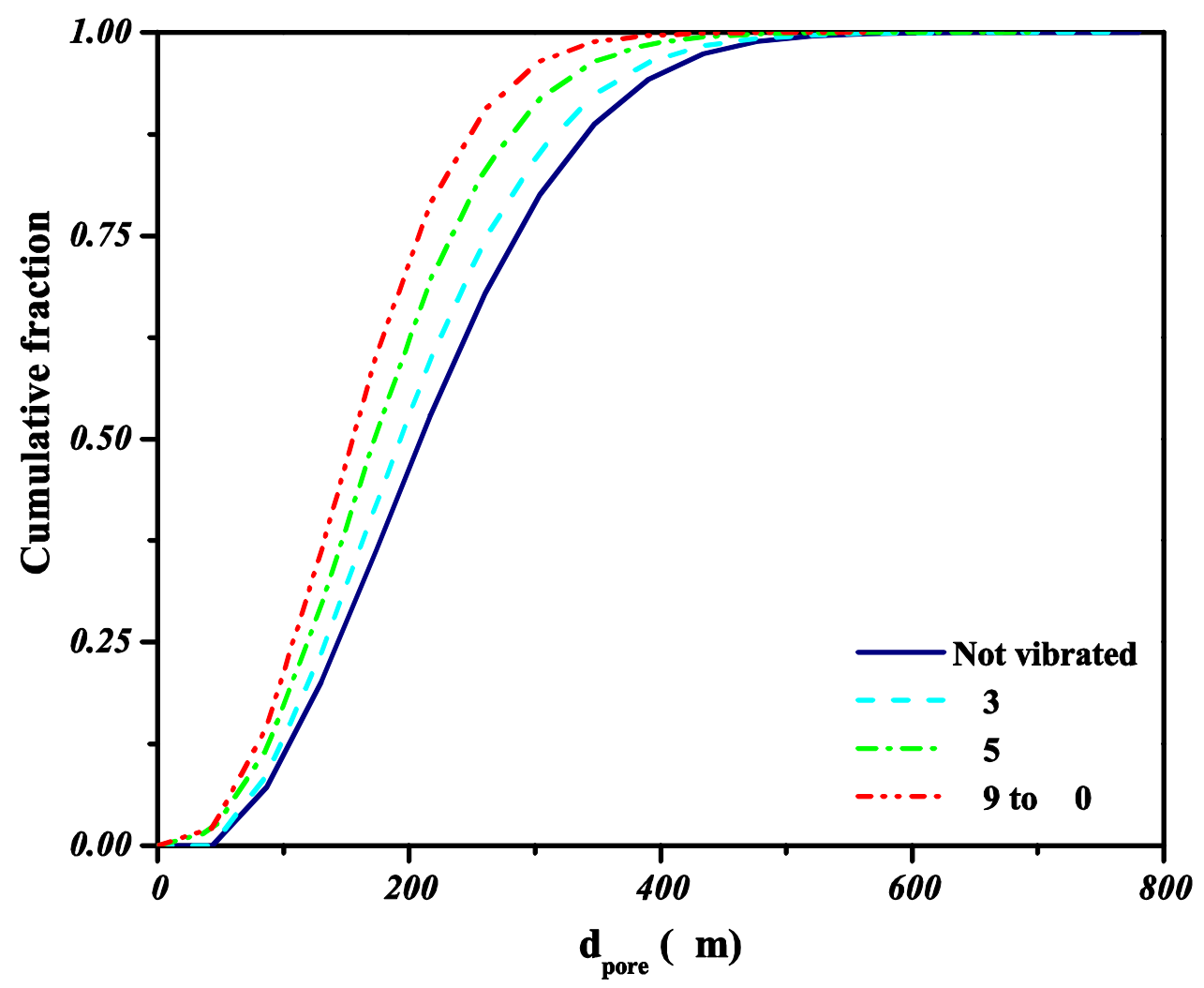


Figure $6 b$

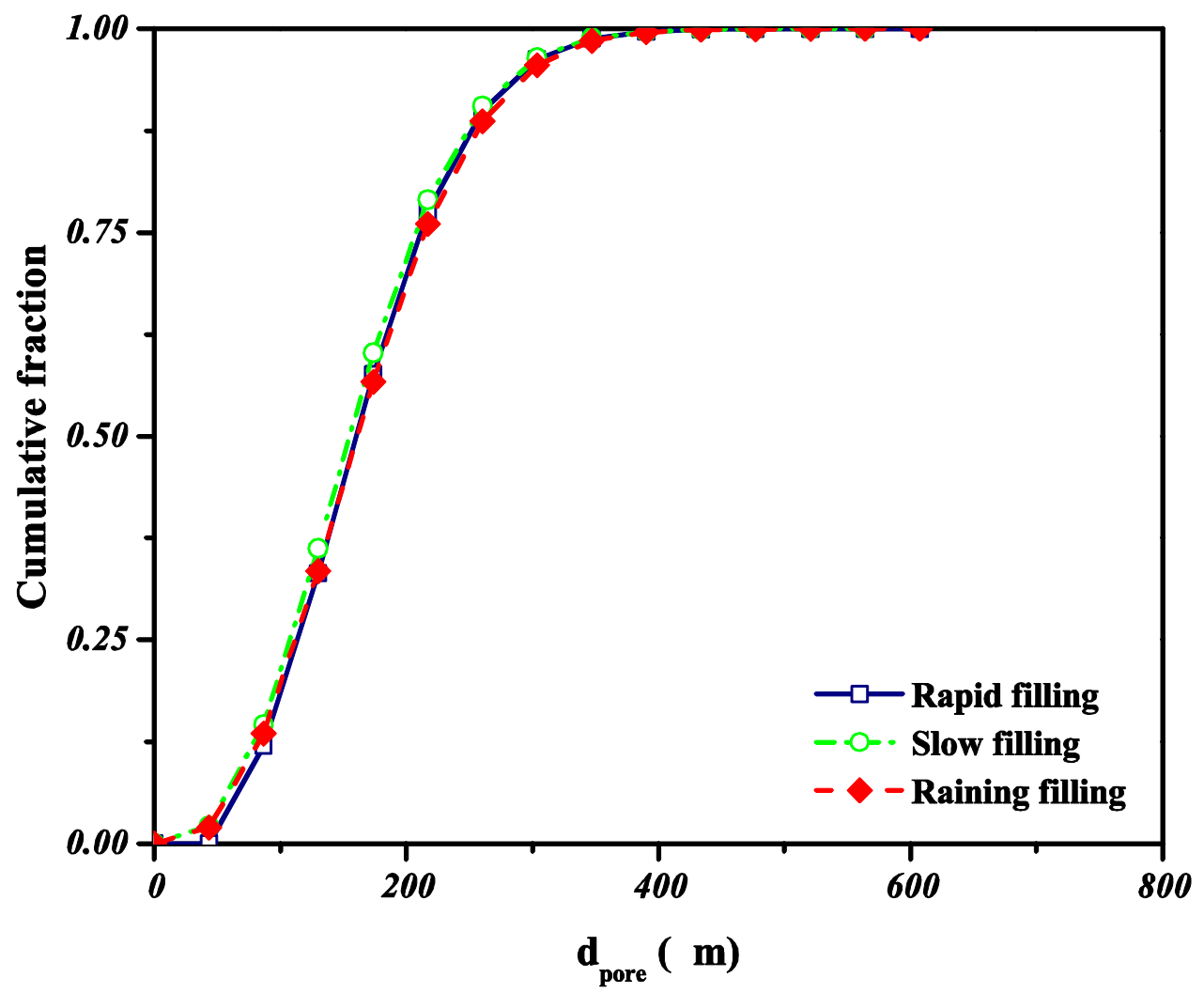


Figure 7

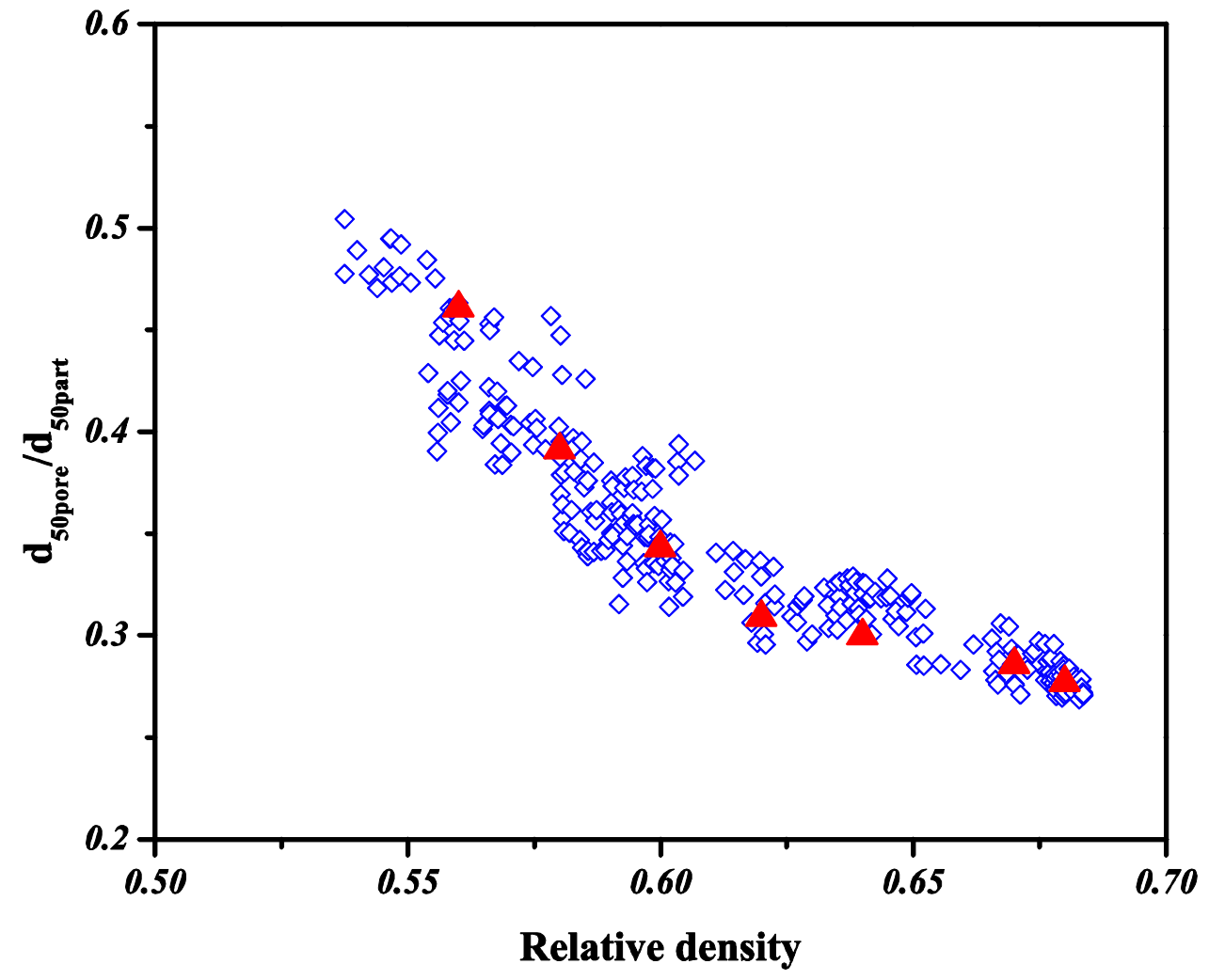


Figure 8

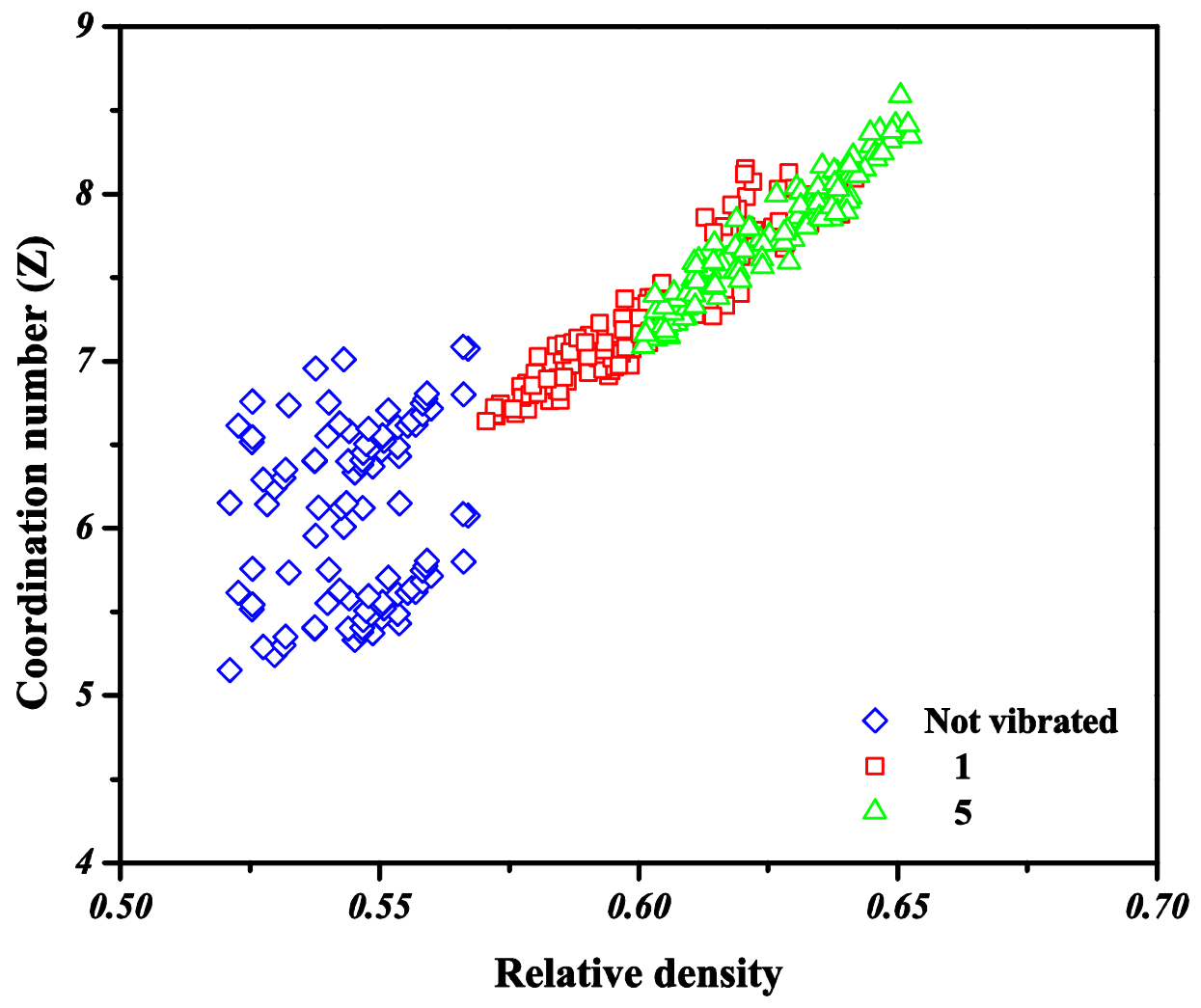


Figure 9a

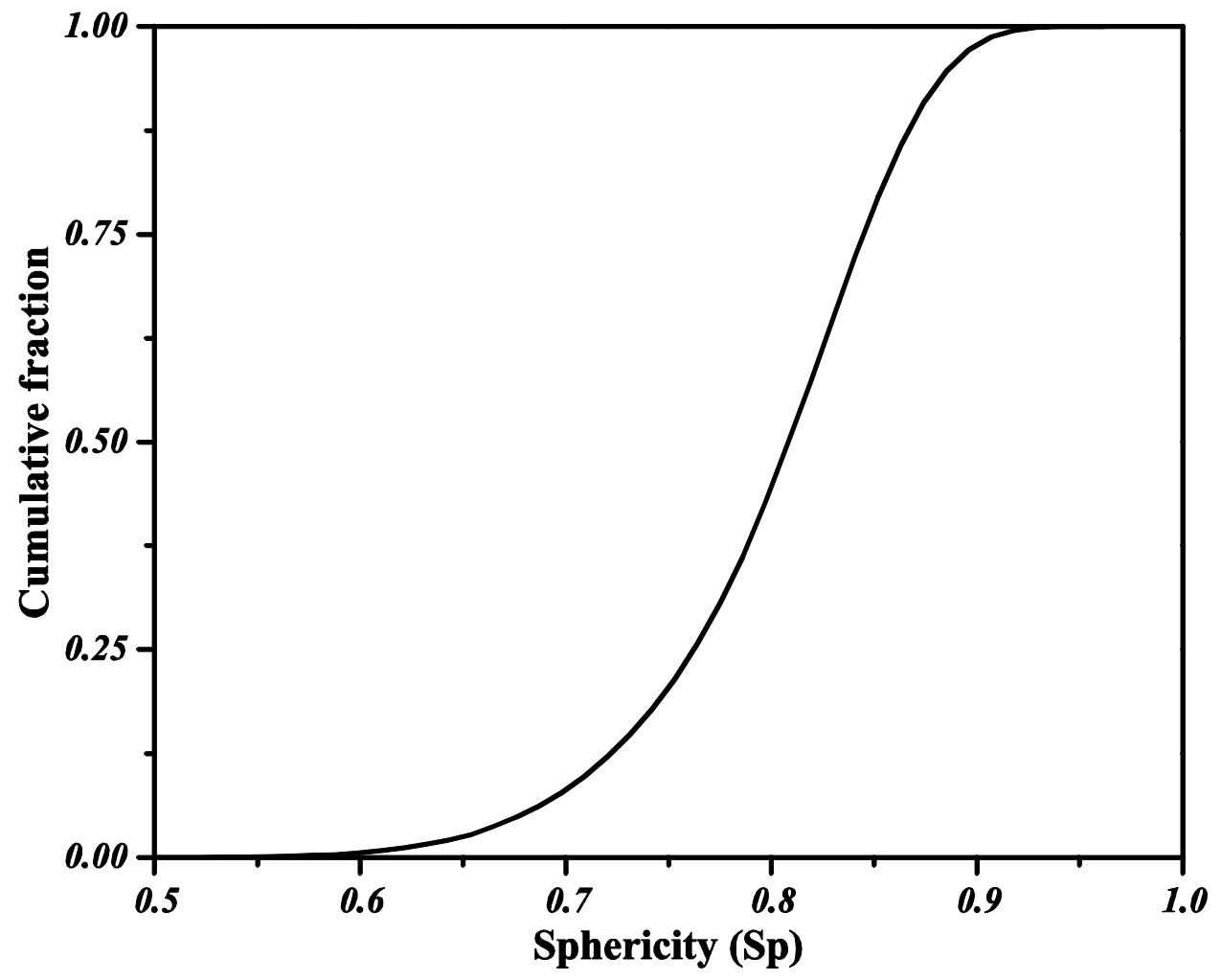


Figure $9 b$

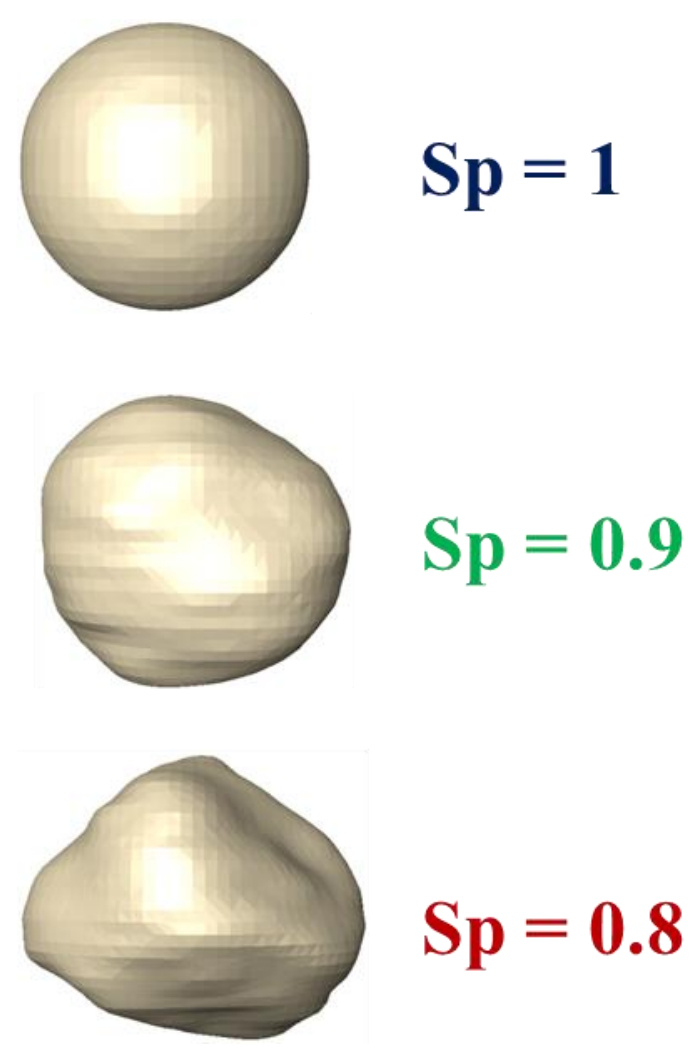


Figure 10a

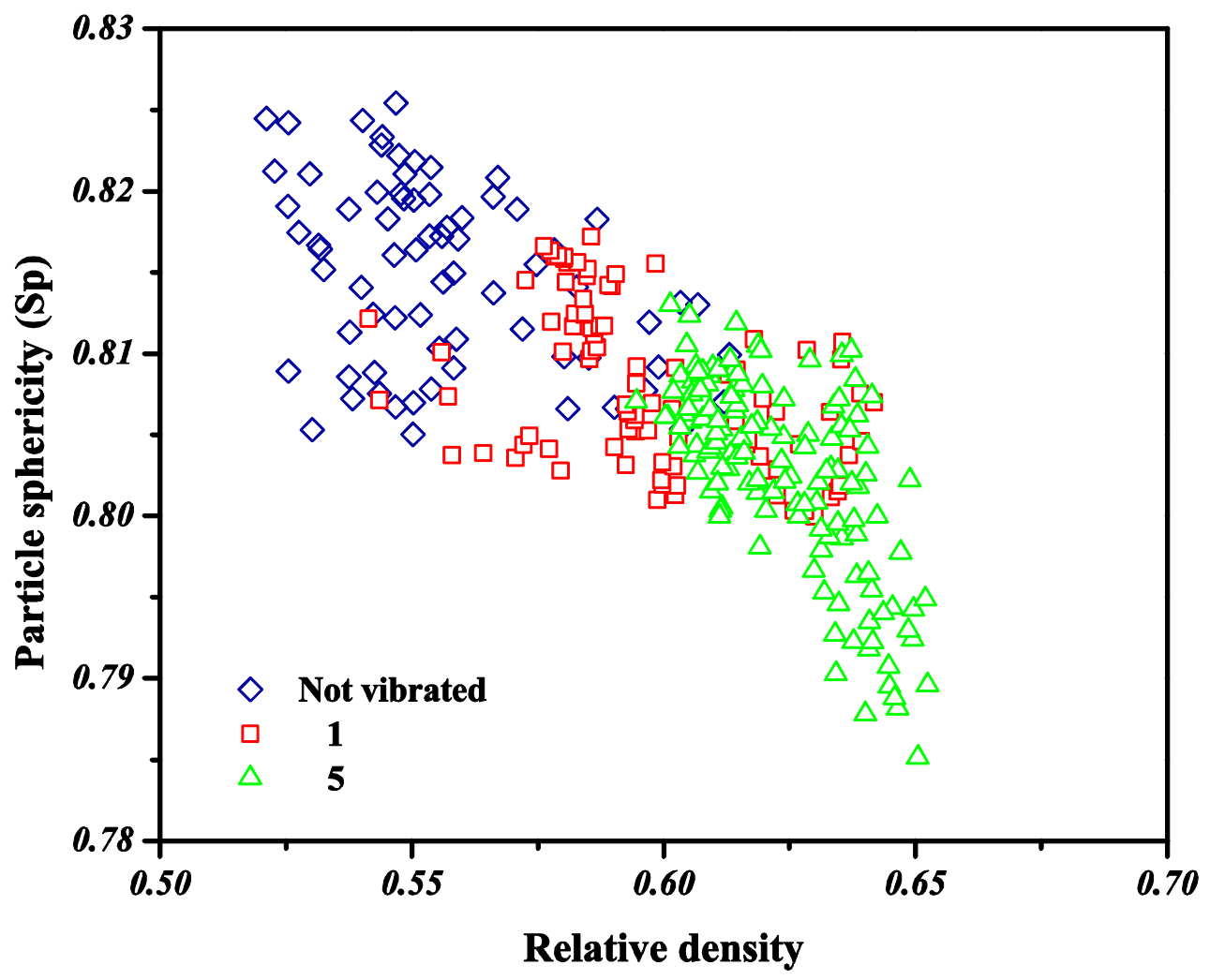


Figure $10 \mathrm{~b}$

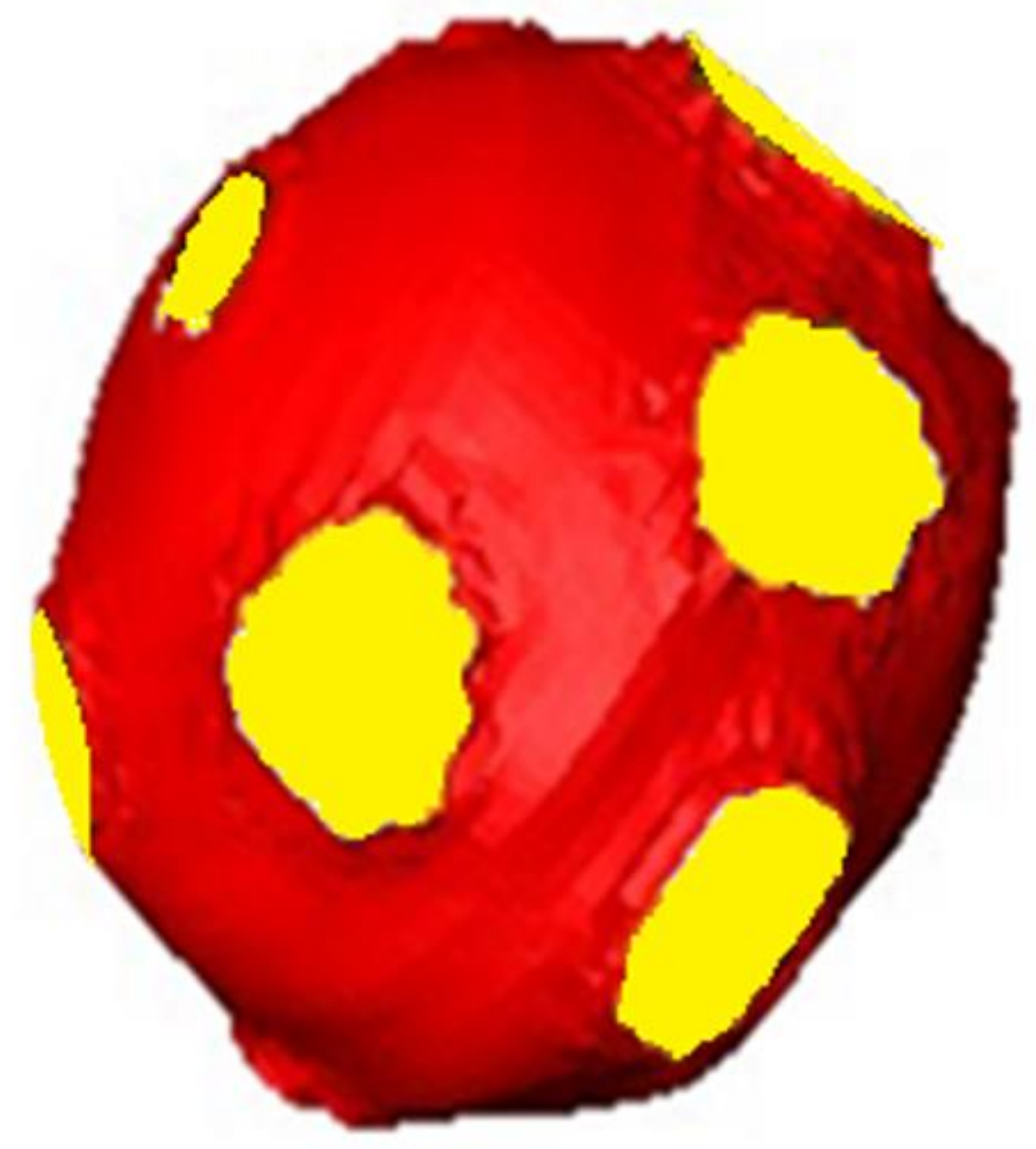

